J. Lake Sci. (湖泊科学) , 2013, 25(1): 65-72

http: //www. jlakes. org. E-mail : jlakes@niglas.ac.cn

(C) 2013 by Journal of Lake Sciences

\title{
鄱阳湖流域干旱气候特征研究
}

闵屾, 严蜜, 刘 健**

(中国科学院南京地理与湖泊研究所, 湖泊与环境国家重点实验室,南京 210008)

摘 要: 本文利用鄱阳湖流域 127 个站点 1960-2007 年逐日降水和温度资料, 选用 $Z$ 指数对翻阳湖流域的气象干旱进 行分析,并将干旱分为偏旱、大旱和特旱三个等级. 研究结果表明鄱阳湖流域干旱基本呈现出南少北多、南强北弱的空间 分布形式. 鄱阳湖流域 7-12 月发生的干旱以偏旱为主, 大旱和特旱主要出现在 1-6 月. 线性趋势变化分析表明, 2000 年以来干旱范围和干旱强度均呈现出增加的趋势, 其中, 2003、2004 和 2007 年的干旱较为严重. 2003 年大部分月份偏旱 范围广、强度大, 全年大旱和特旱出现的范围均较小, 但 3-4 月和 6-7 月的大旱和特旱强度较大; 2004 年大部分月份偏 旱范围和强度均相对较小, 但在 3 月和 6 月出现范围较大且强度较强的大旱和特旱; 2007 年干旱分布更为极端, 仅在 7 、 10 和 11 月出现范围较广或强度较大的偏旱,而在 5 月集中出现面积超过 $80 \%$ 的大早和特旱.

关键词: 鄱阳湖流域; 气象干旱; $Z$ 指数; 季节变化

\section{Climatic characteristics of the drought in Lake Poyang catchment}

MIN Shen, YAN Mi \& LIU Jian

(State Key Laboratory of Lake Science and Environment, Nanjing Institute of Geography and Limnology, Chinese Academy of Sciences, Nanjing 210008, P. R. China)

Abstract: Based on daily rainfall and temperature datasets of 127 stations in Lake Poyang catchment during the period of 1960 2007 , the climatic drought which was classified into slight drought, heavy drought and extreme drought by using $Z$ index was studied in this paper. The results show that the frequency of drought in the south part of Lake Poyang area is less than that in the north part and the strength of drought in the south part is stronger than that in the north part. The slight drought mainly occurred from July to December, while the heavy drought and extreme drought mainly occurred from January to June. The range and strength of the drought have been increased since 2000 year, especially in 2003, 2004 and 2007. The slight drought appeared in most months of 2003 with extensive area and heavy strength. The heavy and extreme drought with small area appeared in most months of 2003 , except in March - April and June - July. The area and strength of slight drought were small in most months of 2004, but the heavy and extreme drought with extensive area and heavy strength appeared in March and June. The slight drought in July, October and November of 2007 occurred in extensive area, but heavy and extreme drought in May occurred in more than 80\% area of Lake Poyang catchment.

Keywords: Lake Poyang catchment; climatic drought; $Z$ index; seasonal variation

鄱阳湖流域位于亚热带湿润季风气候区内, 受东亚季风影响, 降水的季节变化和年际变化均较大, 不仅 洪涝灾害频繁出现,干旱灾害也较严重. 近 50 年统计资料表明,在鄱阳湖区,虽然水灾的经济损失大于旱 灾,但无论是受灾农田面积还是受灾人口, 都是旱灾多于水灾, 说明旱灾对社会经济的影响并不亚于水 灾 ${ }^{[1]}$. 闵寒等 ${ }^{[2]}$ 分析江西省 1995-2006 年雨、水情特征,发现在 1995-2006 年间江西省经历了降水总量由 多到少、空间分布由大范围到局部多点、时间分配由长历时到短时段的转变; 同时他还指出大范围洪涝灾害

* 中国科学院知识创新工程重要方向性项目 (KZCX2-YW-337)、国家重点基础研究发展计划 “973” 项目 (2010CB950102) 和中国科学院战略性先导科技专项项目 (XDA05080800) 联合资助. 2012-03-15 收稿; $2012-$

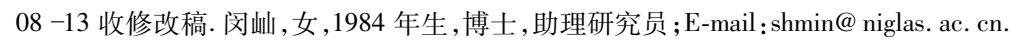

** 通信作者;E-mail:jianliu@ niglas. ac.cn. 
减少、旱灾增多、旱情加重, 防旱抗旱任务更为繁重. 由于降水量的变化是影响极值流量最重要的因素 ${ }^{[3]}$, 蒸 发量的变化也会对径流造成一定程度的影响 ${ }^{[4]}$, 因此, 近年来不少专家学者根据降水量和蒸发量的变化来 分析鄱阳湖流域的干旱 ${ }^{[5-9]}$. 樊任华等 ${ }^{[10]}$ 基于标准化降水指数, 分析了江西夏季干旱时空分布特征,结果表 明夏季干旱较为频繁, 但干旱的发生以轻旱为主, 干旱的频率从 $10 \%$ 到 30\% 不等, 赣南部分地区发生的频率 相对较低. 闵骞等 ${ }^{[11]}$ 根据 7-10 月蒸发总量与 7-10 月降水总量定义干旱指数, 并结合历史记载资料, 分析 了鄱阳湖区近 1000 年来干旱的气候演变特征, 表明从大周期上看, 本世纪鄱阳湖湖区的气候严重干旱属正 常偏少状态; 但从小周期看, 20 世纪前 20 年湖区气候严重干旱为偏多状态, 未来十几年的抗旱形势依然十 分严峻. 因此, 分析鄱阳湖流域的干旱气候特征对人民的生产生活以及社会经济的发展依然有着至关重要 的意义.

以往分析鄱阳湖流域干旱时, 主要针对 7-10 月的干旱, 即伏旱和秋旱, 因为鄱阳湖流域夏、秋季节降 水相对较少, 多发干旱, 且夏、秋季节的干旱容易对农业生产造成严重影响. 虽然春季是鄱阳湖流域的多雨 季节, 但据鄱阳湖水文局数据资料统计, 自 1992 年起, 都昌水文站 3 月上旬至 5 月中旬平均水位正在以每年 $0.13 \mathrm{~m}$ 左右的速度下降, 说明鄱阳湖的春旱正在加剧. 春天是万物复苏、生机勃发的季节, 严重的春旱会给 渔业乃至生态环境造成深远的影响. 另外, 以前的研究工作中, 多选用降水量或蒸发量作为衡量干旱的标 准, 而不同时间尺度、不同地区的降水量、蒸发量变化差异较大, 直接用降水量和蒸发量在时空尺度上相互 比较缺乏合理性, 需要选择更加合理的干旱指数来研究鄱阳湖流域的干旱变化. $Z$ 指数不仅考虑了降水服从 偏态分布的实际, 而且也进行了正态标准化处理 ${ }^{[12]}$, 使之适合不同时间尺度的旱涝监测和评价, 从而得到了 广泛的应用 ${ }^{[13-21]}$. 因此, 本文同样选用 $Z$ 指数作为划分鄱阳湖流域干旱的标准, 且不再局限于 7-10月,而

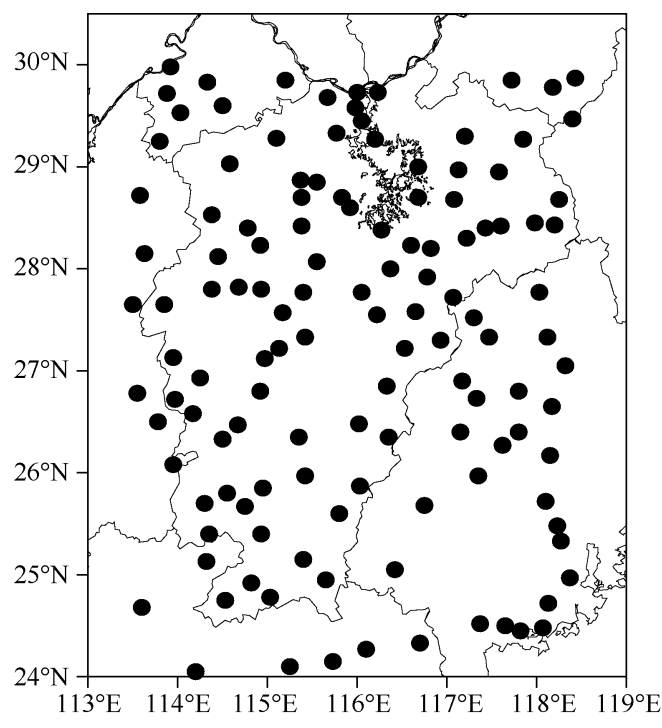

图 1 鄱阳湖流域气象站点分布

Fig. 1 Distribution of meteorological stations in Lake Poyang catchment 是分析全年 12 个月的干旱时空分布特征, 并选取典型 干旱年份研究其季节分布差异.

\section{1 资料与方法}

本文运用国家气象信息中心提供的 1960-2007 年地面高密度台站逐日降水、温度数据, 全国各省共 2466 个观测站,其中基本基准站 756 个,一般站 1668 个,行业站 42 个, 鄱阳湖流域范围内共有 162 个站点. 在使用资料时, 进行了质量控制, 首先剔除在研究时间 段内迁过站的台站. 在缺测值方面, 如果某个站点中连 续缺测的天数超过 $5 \mathrm{~d}$, 那么也将该站点剔除. 没剔除 的站点中, 当出现缺测值时, 采用线性插值的方法进行 处理, 由于剩余站点中缺测值较少, 一般为 $1 \sim 2 \mathrm{~d}$, 因 此对于整体研究影响较小. 基于上述条件, 本文在鄱阳 湖流域 $\left(24^{\circ} \sim 30^{\circ} \mathrm{N}, 113^{\circ} 30^{\prime} \sim 118^{\circ} 30^{\prime} \mathrm{E}\right)$ 范围内选取 了 127 个站点 (图 1).

本文中选用单站 $Z$ 指数来划分旱涝等级. 具体做 法为假定某时段降水量服从 Person III 型分布, 则可将 其概率密度函数转换得到:

$$
Z_{i}=\frac{6}{C_{\mathrm{s}}}\left(\frac{C_{\mathrm{s}}}{2} \varphi_{i}+1\right)^{\frac{1}{5}}-\frac{6}{C_{\mathrm{s}}}+\frac{C_{\mathrm{s}}}{6}, i=1,2 \cdots, n
$$

式中, $C_{\mathrm{s}}$ 为偏态系数, $\varphi_{i}$ 为标准化变量, $n$ 为样本个数. 这里将降水量表示为 $D$, 即有:

$$
C_{\mathrm{s}}=\frac{\sum_{i=1}^{n}\left(D_{i}-\bar{D}\right)^{3}}{n \sigma^{3}}, \varphi_{i}=\frac{D_{i}-\bar{D}}{\sigma}, \bar{D}=\frac{1}{n} \sum_{i=1}^{n} D_{i}, \sigma=\sqrt{\frac{1}{n} \sum_{i=1}^{n}\left(D_{i}-\bar{D}\right)^{2}}
$$


经过 $Z$ 指数变换过程, 将降水量转换成为标准的正 态变量, 以此来减小由于降水分布不均而导致的统计误 差, 由此, 根据标准界值将旱涝分为 7 级 (表 1 ), 将旱涝 等级 $>4$ 的统称为干旱, 旱涝等级 $=5 、 6 、 7$ 的分别称为偏 旱、大旱和特旱.

\section{2 鄱阳湖流域干旱的时间变化}

鄱阳湖流域年降水总量在 1960s 以偏少为主, 1970s 和 1980s 年际变化比较明显, 从 1990 年至 2007 年呈现 出由明显偏多转为偏少的变化趋势 (图 2a). 分析鄱阳湖 流域年平均温度的年际-年代际变化 (图 2b) 可知, 其在 1990s 中期以前以偏低为主, 1997 年以来呈现显著的上

表 1 旱涝等级标准

Tab. 1 Classification of drought and flood

\begin{tabular}{cccc}
\hline 等级 & 类型 & $Z$ 值 & $\begin{array}{c}\text { 所占理 } \\
\text { 论频率 }\end{array}$ \\
\hline 1 & 特涝 & $Z>1.645$ & $5 \%$ \\
2 & 大涝 & $1.037<Z \leqslant 1.645$ & $10 \%$ \\
3 & 偏涝 & $0.524<Z \leqslant 1.037$ & $15 \%$ \\
4 & 正常 & $-0.524 \leqslant Z \leqslant 0.524$ & $40 \%$ \\
5 & 偏早 & $-1.037 \leqslant Z<-0.524$ & $15 \%$ \\
6 & 大早 & $-1.645 \leqslant Z<-1.037$ & $10 \%$ \\
7 & 特早 & $Z<-1.645$ & $5 \%$ \\
\hline
\end{tabular}

升趋势. 由于温度升高可能导致蒸散异常变化,因此,采用日本高桥浩一郎提出的计算公式 ${ }^{[22]}$ 来计算鄱阳湖 流域各站实际蒸散量. 在 2000 年以前, 鄱阳湖流域年蒸散总量与年降水总量呈现出很好的正相关关系, 年 降水总量偏多 (少) 时年蒸散总量偏多 (少);2000 年以来,鄱阳湖流域年降水总量呈现下降的趋势,但是年 蒸散总量依然偏多(图 2c), 这可能是增温显著造成的.
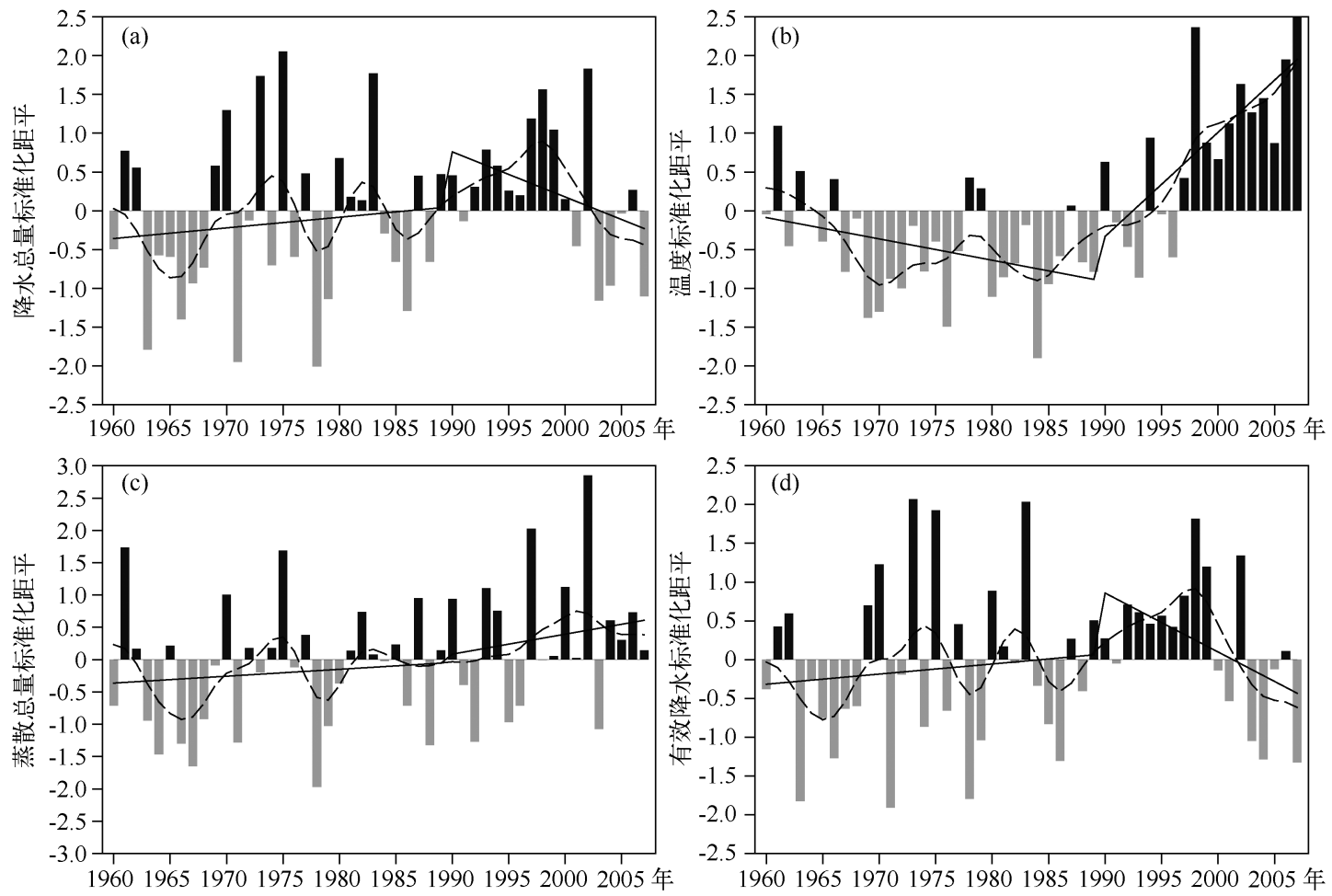

图 2 鄱阳湖流域年平均降水总量 $(\mathrm{a}) 、$ 、温度 $(\mathrm{b})$ 、蒸散总量 $(\mathrm{c})$ 和有效降水量 $(\mathrm{d})$ 标准化距平 以及 11 年滑动平均曲线

Fig. 2 Time series of the normalized annual precipitation amount(a), temperature(b), evaporation(c), effective precipitation amount(d) and their 11-year running average in Lake Poyang catchment

许多研究表明,在全球增暖的背景下,极端天气与气候事件急剧增加,对国民经济和生态环境造成了严 重灾害. 因此, 我们在定义气象干旱指数时, 不仅需要考虑降水异常的作用, 也需要考虑由于增暖导致蒸散 
加剧的影响. 本文以降水量减蒸散量 (下面称为有效降水量) 作为表征干旱强弱的物理量. 鄱阳湖流域有效 降水量的年际变化基本与年降水总量一致, 由于受到增温蒸散加剧的影响,近十年来有效降水量的下降趋 势比年降水总量更加明显, 其中,2003、2004 和 2007 年有效降水量显著偏少 (图 2d). 因此,下面用有效降水 量替代降水量来计算 $Z$ 指数.

首先, 为了定量描述鄱阳湖流域干旱出现站点的多少, 以绝对值大于 0 的年份定义为偏多或偏少年, 绝 对值大于 1 的年份定义为异常偏多或偏少年. 分析发现鄱阳湖流域在 1960s 中期出现干旱 (旱涝等级 > 4) 的站点偏多,1970s 和 1980s 也有异常偏多的年份存在, 如 1971、1978 及 1986 年; 1990s 出现干旱的站点偏 少, 从 2000 年以来又呈现出偏多的趋势, 说明 2000 年以来鄱阳湖流域干旱呈现出增加的趋势, 尤其是 $2003 、 2004$ 和 2007 年干旱站点异常偏多, 这与由有效降水量得到的结果一致, 它们之间呈现显著负相关关 系 $(r=-0.94, P<0.001)$, 即有效降水量偏少 (多) 时, 干旱等级偏大 (小), 这也表明 $Z$ 指数在表征鄱阳湖 流域干旱方面是有效的.

$1970 \mathrm{~s}$ 以来秋、冬季 (11、12 月) 偏旱出现的站点数较多, 另外, 冬季 $1 、 2$ 月在 $1980 \mathrm{~s}$ 中期也有较多站点出 现偏旱; 除 1990s 以外,夏季 (6-8 月) 出现偏旱的站点数也较多; 春季偏旱相对较少 (图 3a). 鄱阳湖流域大 旱主要发生在上半年 (1-6 月), 1960s 初 1-3 月尤其显著; 春季 (3-5 月) 发生大旱的站点相对较多 (图 3b). 鄱阳湖流域特旱也存在比较明显的季节和年代际变化, 1960s 1-6 月出现特旱情况的站点数相对较 多, 1970s 特旱站点数较多的季节出现在 2-4 月, 而 1980s 以来特旱主要出现在 3-6 月 (图 3c).
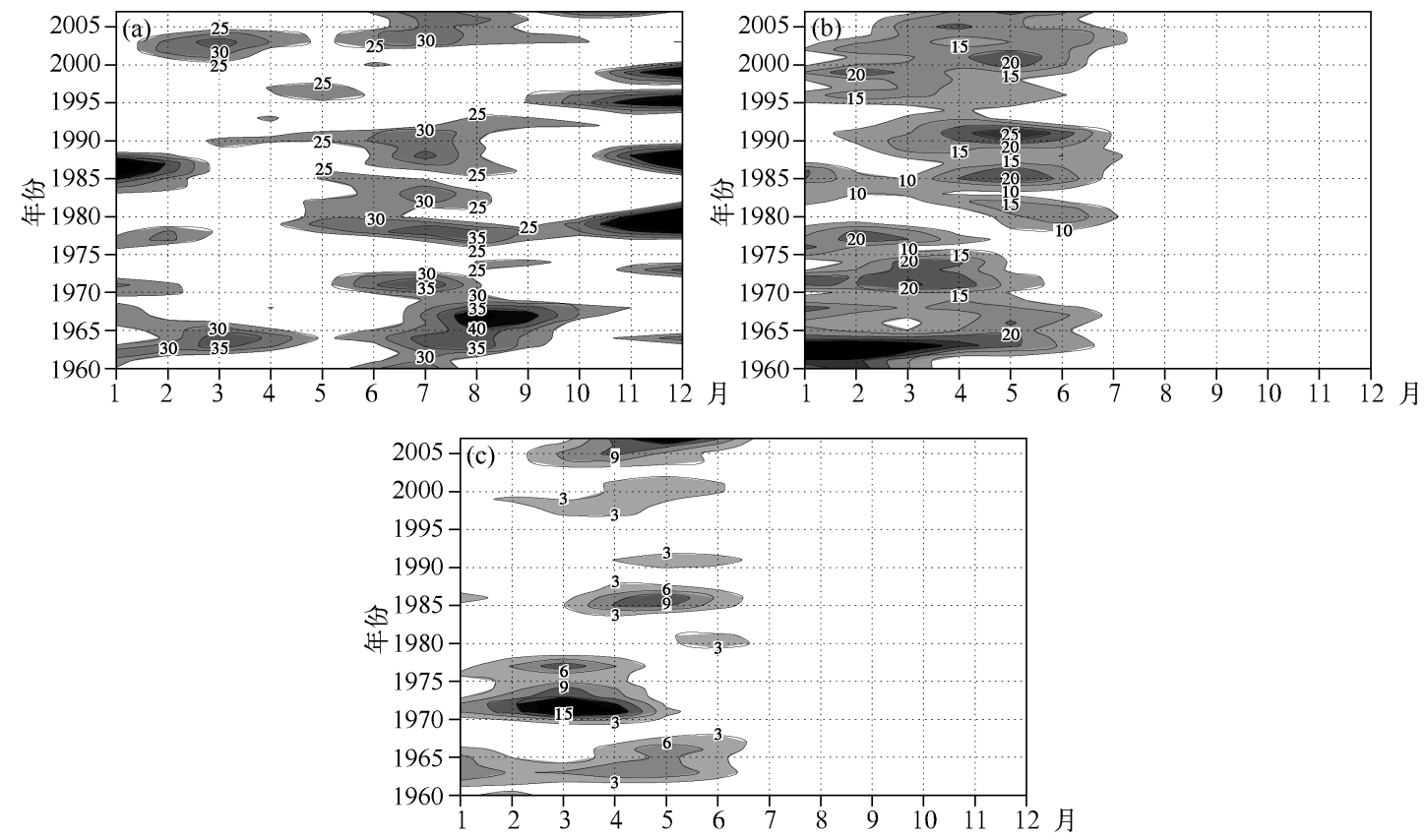

图 3 鄱阳湖流域各级干旱站点数的季节-年际变化: (a) 偏旱; (b) 大旱; (c) 特旱

Fig. 3 Seasonal and interannual variations of the station numbers with different grades of drought occurred in Lake Poyang catchment: (a) slight drought; (b) heavy drought; (c) extreme drought

为了更方便地看出鄱阳湖流域各月发生干旱的情况, 给出各月各等级干旱发生的频率 (图 4), 结果表明 偏旱的极大值出现在夏季的 7 月,发生频率达 $24.0 \%$, 其次为秋季的 11 月,约为 $21.1 \%$; 偏旱的极小值出现 在秋季的 10 月, 发生频率为 $10.4 \%$; 而春季 3 个月份偏旱发生频率均相对较少. 大旱发生频率的季节分布 特征与偏旱不同, 其极大值出现在冬季的 2 月, 发生频率达 $13.0 \%$, 冬季的 $1 、 2$ 月份大旱平均发生频率为 $10.6 \%$ (冬季的 12 月大旱发生频率为 0 ) ; 大旱发生频率的次大值出现在春季的 4 月, 约为 $12.9 \%$, 整个春季 平均大旱发生频率为 $11.3 \%$; 秋季大旱发生的频率最小. 特旱发生频率的季节变化特征与大旱类似, $1-6$ 月 
特旱发生频率较大, 7- 12 月几乎不发生; 且特 旱发生频率最大的 3 个月均出现在春季.

进一步分析干旱发生频率发现, 全年有 3 个月份的干旱发生频率大于 $30.0 \%$, 按大小顺 序依次为春季的 4 月、夏季的 6 月以及冬季的 2 月. 春季干旱平均发生频率为 $30.8 \%$, 其中 $14.8 \%$ 为大旱、特旱;夏季的 7、8 月干旱平均发 生频率为 $25.0 \%$, 其中偏旱占 $22.6 \%$, 而 6 月 干旱发生频率为 $31.6 \%$, 其中 $13.7 \%$ 为大旱、 特旱; 秋季干旱平均发生频率为 $16.9 \%$, 其中 $16.5 \%$ 为偏旱; 冬季的 $1 、 2$ 月干旱平均发生频 率为 $29.3 \%$, 其中 $11.8 \%$ 为大旱、特旱, 而 12 月只有偏旱发生. 上述统计结果说明鄱阳湖流

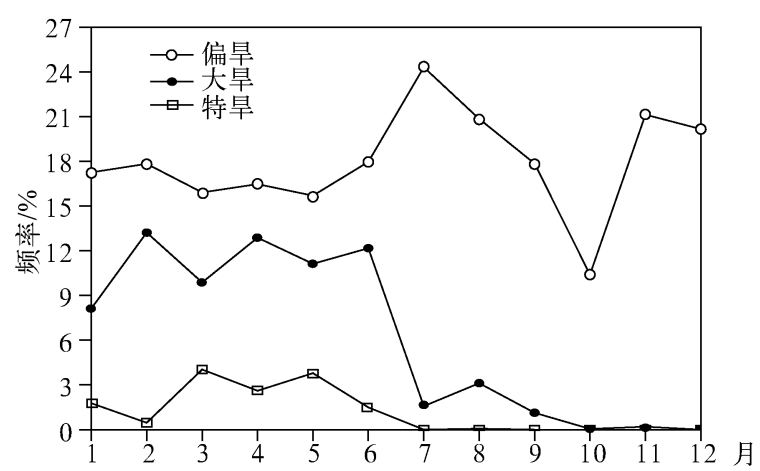

图 4 鄱阳湖流域各级干旱发生频率的季节变化

Fig. 4 Seasonal frequencies of drought with different grades occurred in Lake Poyang catchment 域 7-12 月发生的干旱以偏早为主,而大旱、特 旱主要发生在 $1-6$ 月.

\section{3 鄱阳湖流域干旱的空间分布}

为了避免由于站点分布不均而导致的空间插值以及统计误差, 把 $24^{\circ} \sim 30^{\circ} \mathrm{N}, 113^{\circ} 30^{\prime} \sim 118^{\circ} 30^{\prime} \mathrm{E}$ 范围 内的 127 个站点分成 $1^{\circ} \times 1^{\circ}$ 的小方格, 即共有 $5 \times 6=30$ 个小方格, 计算每个小方格中的站点数 $N$. 某一年每 个小方格中旱涝等级 $>4$ (或旱涝等级 $=5 、 6 、 7$ ) 的站点数 $n$ 与该方格中站点数 $N$ 的比值表示为该格这一年 的干旱 (偏旱、大旱、特旱) 强度,比值大于 0 说明该格这一年出现干旱 (偏旱、大旱、特旱), 比值为 1 说明该 方格内所有站点均出现干旱 (偏旱、大旱、特旱), 即强度达到最大. 所有出现干旱的格点总数表示该年发生 干旱的范围;某一格在 1960-2007 年间干旱强度不为 0 的年份数表示该格发生干旱的频数.

本文利用年 $Z$ 指数对鄱阳湖流域干旱的总体分布特征进行分析. 从鄱阳湖流域干旱出现频数的分布表 明 (图 5a), 极大值出现在江西北部鄱阳湖湖区附近, 达 27 年以上,极小值出现在江西东南部,约为 20 年; 鄱 阳湖流域多年平均干旱强度 (图 5b) 呈现出与干旱频数相反的分布形式, 干旱强度的极小值小于 0.60 , 出现 在鄱阳湖湖区附近, 而极大值大于 0.70 , 出现在江西东南部. 鄱阳湖流域干旱出现频数与多年平均干旱强度 的空间相关系数达到 -0.78 , 超过了 0.001 的显著性水平.
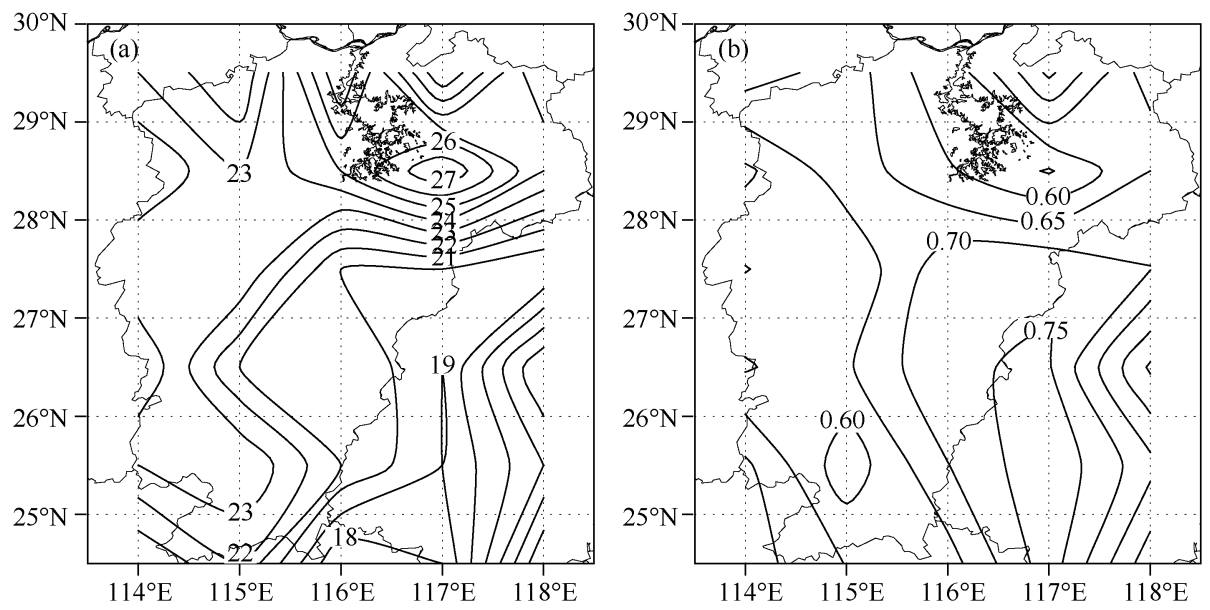

图 5 鄱阳湖流域干旱出现频数 (a) 和平均干旱强度 (b)

Fig. 5 Spatial distribution of frequency (a) and averaged strength(b) of drought in Lake Poyang catchment 
鄱阳湖流域偏旱出现频数的分布形式与干旱频数的分布型基本类似 (图略), 二者的空间相关系数达 0.94 , 显著相关, 其中偏旱极大值为 24 年左右, 极小值小于 14 年. 鄱阳湖流域偏旱强度分布形式也与干旱强 度基本类似, 两者空间相关系数约为 0.84 (图略), 偏旱强度的极大值出现在江西东南部, 大于 0.50 , 极小值 出现在鄱阳湖湖区附近, 小于 0.40 . 鄱阳湖流域大旱、特旱出现频数的分布形式同样与干旱频数基本类似, 极大值出现在鄱阳湖湖区, 有 15 年出现大旱, 6 年出现特旱; 极小值出现在鄱阳湖流域东南部, 出现大旱的 年份小于 10 年, 而出现特旱的年份小于 4 年. 鄱阳湖流域大旱、特旱强度也与干旱强度的分布基本类似(图 略), 鄱阳湖湖区附近大早、特旱强度约为 0.35 和 0.30 , 而江西南部分别达 0.50 和 0.75 以上. 以上结果说 明鄱阳湖流域的各级干旱基本呈现出南少北多,南强北弱的分布形式.

分析干旱范围和干旱强度的变化可知 (图略),2000 年以来干旱范围和干旱强度均呈现增加的趋势, 尤 其是 2003 、2004 和 2007 年. 这三年分别有 26 、29 和 21 个小方格发生干旱, 其中发生大旱和特旱的小方格数 分别为 $22 、 24$ 和 19 ; 这三年干旱强度分别为 $0.84 、 0.85$ 和 0.92 , 而大早和特旱强度为 $0.72 、 0.73$ 和 0.84 . 这 说明这三年干旱发生的范围广、强度大, 与上面得到的结论一致. 因此,下面具体分析这三年干旱的季节分 布特征.

\section{4 鄱阳湖流域典型年份的干旱特征}

利用逐月 $Z$ 指数分析 2003 、2004 和 2007 年各级干旱的季节变化特征. 2003 年除了 $1 、 5$ 和 11 月以外,其 他月份的干旱范围均过半, 极大值出现在 7 月, 整个鄱阳湖流域均出现干旱; 偏旱出现的范围与干旱基本一 致, 只在 3-7 月范围略小; 各个季节出现大旱的范围均不大, 相对较大的月份为 $2 、 3 、 6$ 和 7 月, 约占全流域 面积的 30\% 40\%, 其他月份均在 3 个小方格以内; 另外, 仅在 4 月有 1 个小方格出现特早, 其它月份均无特 旱出现 (图 6a). 2004 年干旱季节变化显著, 仅在 2、3、4、6 和 10 月干旱面积过半, 极大值出现在 6 月; 偏旱范 围与干旱范围较一致, 仅在 3 月和 6 月比干旱范围小; 出现大范围大旱、特旱的月份主要集中在 3 月和 6 月,
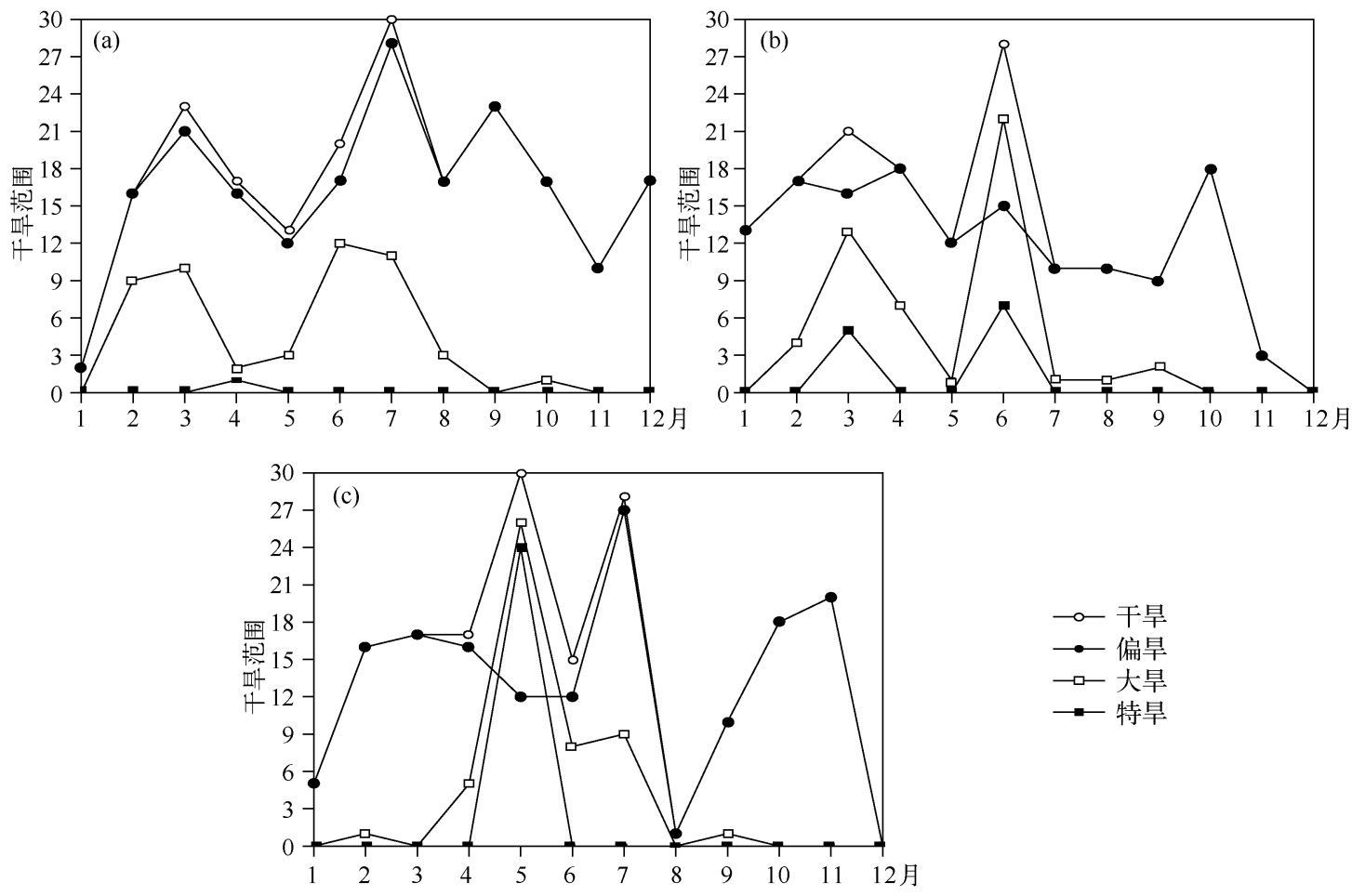

图 6 典型干旱年份各级干旱范围的季节变化: (a) 2003 年; (b) 2004 年; (c) 2007 年

Fig. 6 Seasonal variations of drought range with different grades occurred in 2003(a), 2004(b) and 2007(c) 
其中 6 月有 22 个小方格出现大早以及 7 个小方格出现特早, 分别约占整个鄱阳湖流域面积的 $73.3 \%$ 和 23.3\%（图 6b). 2007 年干旱的季节变化也非常明显,5 月整个鄱阳湖流域均出现干旱,7 月也有约 $93.3 \%$ 的 范围出现干旱, $1 、 8$ 和 12 月出现干旱的范围小于 $20.0 \%$; 偏旱出现范围最大的月份为 $7 、 10$ 和 11 月也有 $60.0 \%$ 以上的范围出现偏旱; 大旱、特旱的变化较为极端, 主要集中在 5 月出现, 大旱范围达 $86.7 \%$, 而特旱 范围也达 $80.0 \%$ (图 6c).

2003 年 $2 、 3 、 7$ 和 12 月的干旱强度在 0.70 以上,偏旱强度的变化形式与干旱强度类似,极大值出现在 12 月,约为 0.75 , 全年平均偏旱强度较大,约为 0.51 ; 大旱强度在 3.6 和 7 月较大, 达 0.40 以上; 特旱虽然只 出现在 4 月,但强度达 0.75 (图 7a). 2004 年干旱强度极大值出现在 6 月,仅 4 个月份干旱强度大于 0.50 ; 偏 旱强度在 $1-10$ 月变化幅度较小,约在 $0.30 \sim 0.50$ 之间,全年平均偏旱强度约为 0.38 ; 大旱强度极大值出 现在 6 月, 为 0.55 ,特旱强度在 3 月和 6 月较大,分别为 0.54 和 0.49 (图 7b). 2007 年 $5 、 7$ 和 11 月干旱强度 大于 0.70 , 极大值出现在 5 月,达 0.95 ; 偏旱强度的极大值出现在 11 月,为 0.75 ,除 $7 、 10$ 和 11 月以外,其它 月份的偏旱强度均小于 0.50 , 全年平均偏旱强度约为 0.39 ; 大旱强度极大值出现在 4 月, 为 0.51 , 而 5 月大 旱、特旱强度均较大,分别为 0.44 和 0.55 (图 7c).
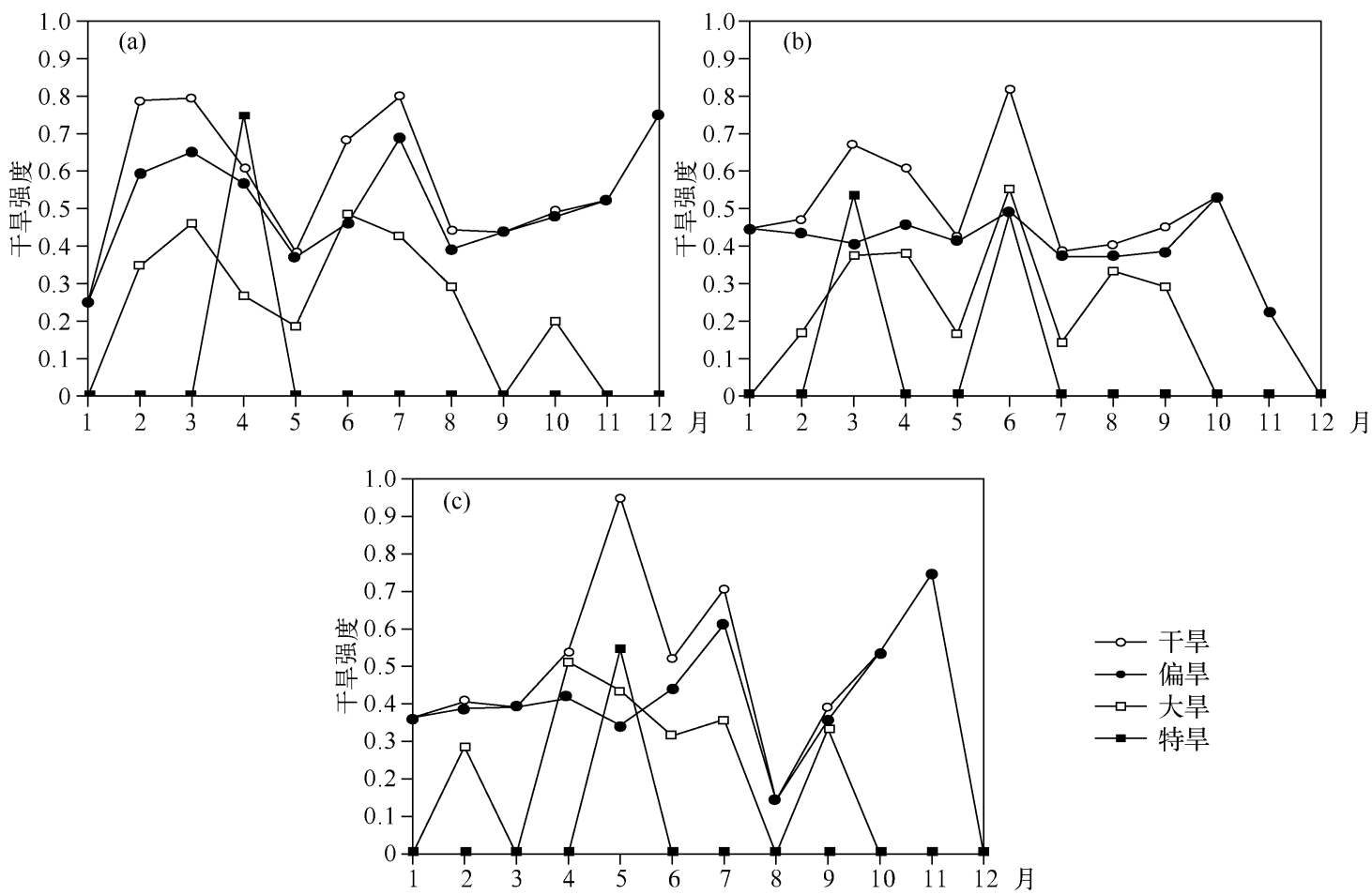

图 7 典型干旱年份各级干旱强度的季节变化: (a) 2003 年; (b) 2004 年; (c) 2007 年

Fig. 7 Seasonal variations of drought strength with different grades occurred in 2003(a), 2004(b) and 2007 (c)

\section{5 结论}

本文利用鄱阳湖流域 127 个站点 1960-2007 年的逐日降水以及温度资料,选用 $Z$ 指数分析了鄱阳湖流 域干旱的气候特征. 主要结论归纳如下:

1) 鄱阳湖流域出现干旱的站点总数在整个研究时段内呈现出先减少再增加的趋势, 2000 年以来鄱阳 湖流域干旱站点数明显增加,尤其是 2003 、2004 和 2007 年. 这与鄱阳湖流域区域平均年有效降水总量的年 际变化和趋势变化特征一致,说明了 $Z$ 指数表征鄱阳湖流域干旱特征的有效性.

2 ) 鄱阳湖流域 7-12 月偏旱发生频率相对较高,且这几个月的干旱主要以偏旱为主,基本不发生大旱、 
特旱; 大旱、特旱主要集中发生在 $1-6$ 月, 其中以春季的发生频率最高. 可见上半年尤其是春季鄱阳湖流域 的防旱形势更为严峻,应针对这一形势做好防旱工作.

3) 鄱阳湖流域干旱基本呈现出南部发生次数较少但强度相对较大, 而北部发生次数较多但强度相对较 小的空间分布形式. 应针对这种区域分布特征,分别进行防旱工程的建设.

4）2003、2004 和 2007 年的干旱均呈现出范围广强度大的特征,但它们存在不同的季节变化. 2003 年除 1,5 和 11 月以外, 其它月份均有大面积偏旱发生, 且全年平均偏旱强度达 0.51 , 全年大旱、特旱出现的范围 均相对较小, 但 $3 、 4 、 6$ 和 7 月的大旱、特旱强度较大; 2004 年仅在 $2 、 3 、 4 、 5$ 和 10 月出现较大面积偏旱, 且在 3 月和 6 月出现范围大且强度强的大旱、特旱; 2007 年干旱季节分布较为极端, 7 月偏旱面积达总面积的 $90 \%, 11$ 月偏旱强度达 0.75 , 但全年平均偏旱强度仅为 0.39 , 大旱、特旱主要集中在 5 月出现, 面积均达到 总面积的 $80 \%$ 以上, 且强度也较大. 虽然 3 年中干旱的出现存在较大的季节差异, 但大旱、特旱均出现在上 半年,而下半年主要以偏旱为主. 可见不同年份由于环流形势的不同, 干旱发生的时间及区域均有所不同, 应加强环流形势与干旱发生之间关系的研究,做好预测工作,为防旱抗旱提供理论依据.

\section{6 参考文献}

[1] 闵 骞. 平原湖区也须重视防早一以鄱阳湖区为例. 中国减灾, $2003,3: 39-41$.

[ 2 ] 闵 骞,芦应根, 郭玉银. 近 12 年江西省雨水情特征与防汛抗旱形势分析. 中国防汛抗旱, 2008, (1):40-46.

[ 3 ] 孙 鹏,张 强,陈晓宏. 鄱阳湖流域枯水径流演变特征、成因与影响. 地理研究,2011,30(9):1702-1712.

[ 4 ] 郭 华, 苏布达, 王艳君等. 鄱阳湖流域 1955-2002 年径流系数变化趋势及其与气候因子的关系. 湖泊科学, 2007, 19(2) : :163-169.

[ 5 ] 刘福茂,刘玉山. 江西干旱指数分析. 江西水利科技,2004,30(1):13-14.

[ 6 ] 闵寒. 鄱阳湖区干早与变化. 江西水利科技,2006,32 (3):125-128.

[ 7 ] 李玉林,杨 梅,黄少平等. 江西省夏季干旱特征分析. 应用气象学报, 2003,14(增刊) : 161-169.

[8] 闵骞. 鄱阳湖干旱的定量判别与抗旱分析. 水资源研究, 2007,28(1):5-7.

[9] 闵 寒. 本世纪初江西省旱情与抗旱分析. 水资源研究, 2007,28(3):33-35.

[10] 森任华,刘成林. 基于 SPI 的江西夏季干旱时空特征分析. 江西水利科技,2008,34(4):240-243.

[11］闵 寒,闵 聑. 鄱阳湖区干旱演变特征与水文防旱对策. 水文, 2010,30(1):84-88.

[12] 幺枕生,丁裕国. 气候统计. 北京:气象出版社, 1990.

[13] 鞠笑生,杨贤为, 陈丽娟等. 我国单站旱涝指标确定和区域旱涝级别划分的研究. 应用气象学报, 1997,8 (1): 26-33.

[14] 高 波,陈乾金,任殿东. 江南南部一华南北部前汛期严重旱涝诊断分析. 应用气象学报, 1999,10(2):219-226.

[15］魏风英,张 婷. 东北地区干旱强度频率分布特征及其环流背景. 自然灾害学报,2009,18(3):1-7.

[16] 郭 锐,智协飞. 中国南方旱涝时空分布特征分析.气象科学,2009,29(5):598-605.

[17] 李景刚, 李纪人, 黄诗峰等. 基于 TRMM 数据和区域综合 Z 指数的洞庭湖流域近 10 年旱涝特征分析. 资源科学, $2010,32(6): 1103-1110$.

[18］袁文平,周广胜. 标准化降水指标与 Z 指数在我国应用的对比分析. 植物生态学报, 2004, 28 (4):523-529.

[19］周后福,方 茸,张建军等. 基于 SVD 和修正 Z 指数的汛期旱涝预测及其应用. 气候与环境研究, 2010,15 (1): 64-72.

[20］杨晓华,杨小利. 基于 $Z$ 指数的陇东黄土高原干旱特征分析. 干旱地区农业研究,2010,28(3):248-253.

[21] 王 宏, 余锦华,李宗涛等. 基于 $Z$ 指数的河北省旱涝多尺度变化特征. 气象与环境学报, 2012,28(1):43-47.

[22] 高杯浩一郎. 月平均气温、月降水量以及蒸发散量的推定方式. 天气 (日本), 1979,26 (12):759-763. 